\title{
MEDIOS DE COMUNICACIÓN Y PROCESOS JUDICIALES: UNA MIRADA DESDE LA JURISPRUDENCIA CONSTITUCIONAL *
}

\section{Media and judicial processes: A look from constitutional jurisprudence}

Jorge Enrique Carvajal Martínez ${ }^{* *}$

Recepción: 19 de febrero de 2021. Aceptación: 29 de julio de 2021. DOI: http:/ /dx.doi.org/10.21017/Rev.Repub.2021.v31.a111

\section{RESUMEN}

Este texto tiene por objetivo exponer los límites a los juicios paralelos por parte del derecho colombiano. El presente artículo responde a la siguiente pregunta de investigación: ¿Qué límites constitucionales existen entre el derecho a la libertad de expresión de los medios de comunicación en el caso de la cobertura mediática a los procesos judiciales y los juicios paralelos que surgen de este hecho noticioso? Todo a través de un método de investigación cualitativo, basado en un diseño de investigación documental, que dé cuenta del estado actual de la discusión.

Palabras clave: medios de comunicación, juicios paralelos, procesos judiciales.

\begin{abstract}
This text aims to set the limits on parallel trials by Colombian law. This article answers the following research. What constitutional limits exist between the right to freedom of expression of the media, in the case of media coverage of judicial processes and parallel trials?. All through a qualitative research method,
\end{abstract}

* Artículo resultado de investigación que se enmarca en el proyecto del grupo de investigación «Conflicto y Criminalidad» de la Universidad Católica de Colombia.

* Doctor en sociología jurídica e instituciones políticas, tesis con mención de reconocimiento, Universidad Externado de Colombia. Magíster en Estudios Políticos del Instituto de Estudios Políticos y Relaciones Internacionales (IEPRI) de la Universidad Nacional. Especialista en sociología jurídica, Universidad Externado de Colombia. Abogado, Universidad Nacional, y Licenciado en Ciencias Sociales, Universidad Distrital. Docente de la Universidad Católica de Colombia y de Universidad Nacional de Colombia. Correo electrónico: jecarvajalma@gmail.com; jecaravajal@ucatolica.edu.co . 
based on a documentary research design the at gives an account of the current state of the discussion.

Keywords: media, parallel trials, judicial processes.

\section{INTRODUCCIÓN}

Los medios de comunicación tienen una función social fundamental para la sociedad, ya que por medio de su trabajo los ciudadanos se forman una idea de la realidad. En la actualidad, los avances tecnológicos han abierto nuevos canales de comunicación, que han desplazado poco a poco los medios de información tradicionales (noticieros radiales, programas de televisión y periódi$\cos$ ), sin que esto implique que estas empresas hayan desaparecido, sino que se han adaptado a las plataformas virtuales.

A pesar de que el internet ofrezca la oportunidad para crear fuentes de información independientes, los usuarios aún utilizan a las empresas de comunicación conocidas y adaptadas a estos nuevos formatos. Contrariamente a lo que afirmaba Vattimo (1990), la disponibilidad de información no ha hecho que las sociedades sean más transparentes, pues la cantidad de información hace que los usuarios se sientan sumergidos en un océano inabarcable de información, que los obliga a acudir a los medios tradicionales por una certeza que no pueden encontrar por ellos mismos.

Los medios de comunicación al igual que los usuarios deben seleccionar, dentro de la oferta de información, las noticias que harán parte de su agenda. ¿Qué información presentarán? ¿Cómo deben presentar la información? ¿Qué noticias son más importantes que otras? Aunque estas preguntas puedan parecer objetivas y libres de consideraciones por parte de la dirección del medio, es un proceso lleno de subjetividad y conveniencia.

$\mathrm{Al}$ entrar los medios en una lógica neoliberal, se sumergieron bajo el modelo de la oferta y la demanda. Si las noticias no son relevantes para una audiencia, no tendrán el rating necesario para ser consideradas por una agencia publicitaria. Asimismo, las noticias que afecten a otros grupos de poder pueden repercutir negativamente en el medio de comunicación, por lo que son frecuentemente eliminadas de la agenda mediática y reemplazadas por otras noticias políticamente «neutrales» (Chomsky \& Herman, 2000).

Dentro de las noticias menos incómodas para el poder y con más rating, se encuentran las noticias relacionadas con la criminalidad. Los hurtos, los homicidios y las capturas causan gran interés en una audiencia temerosa de su rea- 
lidad. Aunque en algunos estudios, especialmente provenientes de otros contextos sociales, se hable de la falta de correspondencia entre la sensación de inseguridad y el delito en sí, lo que se afirma es que el problema de la inseguridad es más una agenda de la política que promueve el populismo punitivo (Carvajal, 2019). En Latinoamérica, las dimensiones de la criminalidad pueden justificar la preocupación de algunos usuarios, especialmente, los provenientes de las clases excluidas, que son los que sufren en mayor medida la victimización y la selectividad del sistema penal (Zaffaroni, 2018).

Así, los mass media crean una realidad con muy pocos elementos, que excluyen asuntos que deberían discutirse públicamente. Asimismo, distorsionan la realidad y desvían el debate hacia asuntos que no incomodan políticamente. La criminalidad entra a ser uno de los puntos principales del debate, lo cual repercute en la configuración de las instituciones penales.

La influencia de los medios en las instituciones penales se ha estudiado bajo diferentes conceptos: el populismo punitivo, la política criminal mediática y los juicios paralelos. Los dos primeros se centran en la primera fase de la criminalización, la creación legal. Según estos estudios, los medios de comunicación al distorsionar la realidad y centrarse insistentemente en la cuestión criminal, provocan una reacción en la sociedad de inconformidad y rechazo con el tratamiento de la seguridad, lo cual es aprovechado por algunos políticos que obtienen réditos electorales a través de la promoción de la cárcel como medida principal (Sozzo, 2018). A su vez, los mass media se encargan de explicar y proporcionar soluciones a la inseguridad, que son de carácter exclusivamente penales. De ahí que la sociedad pida un aumento de penas e ignore otras posibles soluciones. De esta manera, los mass media introducen a la sociedad en un pensamiento circular sobre la criminalidad. Los crímenes se explican por la falta de penas y su reducción depende del aumento de estas.

A diferencia de los primeros dos conceptos, los juicios paralelos se centran en la segunda fase de la criminalización, la judicialización de los individuos que hayan quebrantado el sistema penal. En esta fase, se cuestiona la presión indebida que los medios de comunicación ejercen sobre las decisiones de los jueces al discutir y al llevar un juicio simultáneo, que en ocasiones contraría las decisiones en derecho (Garcia-Perrote Forn, 2017).

Este texto tiene por objetivo exponer los límites a los juicios paralelos por parte del derecho colombiano. El presente artículo responde a la siguiente pregunta de investigación: ¿Qué límites constitucionales existen entre el derecho a la libertad de expresión de los medios de comunicación en el caso de la cobertura mediática a los procesos judiciales y los juicios paralelos que surgen 
de este hecho noticioso? La hipótesis propone necesidad de establecer límites jurisprudenciales frente a la evidente influencia que los medios de comunicación ejercen en los procesos judiciales, en particular cuando el hecho noticioso se transforma en juicios paralelos que no son otra cosa que los juicios de valor emitidos por los medios de comunicación masiva frente a la información obtenida en el desarrollo de un proceso judicial. Para esto, en primer lugar, se abordará jurisprudencialmente el derecho a la libertad de expresión en el Sistema Interamericano y la Corte Constitucional. En segundo lugar, se expondrá los alcances del debido proceso. Y, por último, se hará un análisis sobre los juicios paralelos. Todo a través de un diseño de investigación documental, que dé cuenta del estado actual de la discusión.

\section{LIBERTAD DE EXPRESIÓN, INFORMACIÓN Y PRENSA DES- DE LA CORTE CONSTITUCIONAL COLOMBIANA}

La libertad de expresión es un derecho que ha sido reconocido en múltiples instrumentos internacionales y nacionales. La Declaración Universal de los Derechos Humanos y el Pacto Internacional de Derechos Civiles y Políticos establecen que el derecho a tener una opinión y a opinar libremente es fundamental para la consolidación de las sociedades democráticas, por lo cual debe ser garantizado y promovido, de manera que la investigación y la transmisión de la información no puedan ser limitadas indebidamente por fronteras de ningún tipo, ni menos por la censura.

Este derecho está directamente asociado con la promoción del diálogo, el desarrollo y la democracia (Oficina de la UNESCO en Montevideo, párr. 1). En la Declaración de Principios sobre la Libertad de Expresión, se establece que este es un derecho fundamental, inalienable e inherente a todas las personas. Asimismo, su ejercicio no depende del género, la raza, la nacionalidad, el idioma y la religión. La igualdad es fundamental al momento de entender este derecho, ya que ningún criterio diferencial puede justificar su vulneración (Comisión Interamericana de Derechos Humanos, 2000).

La Corte Interamericana de Derechos Humanos ha categorizado el derecho a la libertad de expresión en dos dimensiones: una individual y otra colectiva. La primera dimensión se centra en el derecho a recibir, buscar y difundir información de manera libre; mientras que la dimensión colectiva aborda los aspectos sociales de la difusión de opiniones, entendiendo que con el ejercicio de este derecho se está construyendo una visión mucho más compleja de la realidad, que no solo parte de una fuente, sino que se alimenta de diferentes puntos de vista, experiencias y opiniones (Comisión Interamericana de Derechos Humanos, 2010, párr. 13-14). 
El derecho a la libertad de expresión permite el diálogo entre los ciudadanos, lo cual se ve reflejado en la discusión de los asuntos públicos y en un debate que puede promover el cambio y el control al poder. Por esta razón, se asocia con el fortalecimiento de la democracia. En palabras de la Comisión Interamericana de Derechos Humanos en el documento Antecedentes e Interpretación de la Declaración de Principios:

El respeto y protección de la libertad de expresión adquiere una función primordial, ya que sin ella es imposible que se desarrollen todos los elementos para el fortalecimiento democrático y el respeto a los derechos humanos. El derecho y respeto de la libertad de expresión se erige como instrumento que permite el intercambio libre de ideas y funciona como ente fortalecedor de los procesos democráticos, a la vez que da (sic) otorga a la ciudadanía una herramienta básica de participación. Asimismo, a través de los comunicadores sociales, la ciudadanía adquiere el poder de participar y/o controlar el desempeño de las acciones de los funcionarios públicos. (Comisión Interamericana de Derechos Humanos, párr. 7)

De lo anterior, se deriva la relación indisoluble entre la libertad de expresión y la libertad de prensa, ya que un ejercicio libre de la prensa permite a los individuos recibir información sobre lo que está aconteciendo en la sociedad. Así, los medios de comunicación masiva construyen una idea de la realidad sobre la cual posteriormente se van a formar las opiniones de los ciudadanos.

En Colombia, el derecho a la libertad de expresión es clasificado como un derecho fundamental que responde a un marco nacional regido por el Estado social de derecho, y a un marco internacional regido por los tratados de derechos humanos, que por medio del bloque de constitucionalidad hacen parte del ordenamiento jurídico colombiano. Específicamente, la Constitución del 91, en su artículo 20, establece que:

Se garantiza a toda persona la libertad de expresar y difundir su pensamiento y opiniones, la de informar y recibir información veraz e imparcial, y la de fundar medios masivos de comunicación.

Estos son libres y tienen responsabilidad social. Se garantiza el derecho a la rectificación en condiciones de equidad. No habrá censura.

Jurisprudencialmente, la Corte Constitucional, teniendo como referente a los instrumentos internacionales, ha desarrollado los alcances de este artículo. Estos son algunos de los principales elementos que conforman la libertad de expresión: la libertad de expresión en sentido estricto, que defiende la libertad de difundir el propio pensamiento por cualquier medio o forma de expresión. La libertad de información, que encierra el derecho a buscar e informar sobre 
hechos, opiniones e ideas; la libertad de informar sobre estos por cualquier medio; y la libertad y el derecho a recibir información imparcial y veraz. Y, por último, la libertad de prensa, que da el derecho a crear medios de comunicación masiva y defiende su funcionamiento, prohibiendo la censura.

A pesar de que la libertad de prensa es uno de los fundamentos de las sociedades democráticas, no puede tener un carácter absoluto. El mal ejercicio de este derecho puede tener efectos contraproducentes para la sociedad. Por esta razón, se prohíben los contenidos que instiguen al genocidio, que hagan apología al delito y a la guerra. Asimismo, en el caso de que los contenidos presentados no se correspondan a la realidad, se tendrá el derecho a la rectificación, lo que asegura el derecho de los afectados.

En reiterada jurisprudencia, la Corte Constitucional se ha referido a la responsabilidad social de los medios de comunicación, fijando cuatro criterios que limitan el ejercicio de los derechos a la libertad de expresión y a la libertad de prensa, los cuales se exponen a continuación: distinción entre información y opinión; la veracidad de la información; la imparcialidad; y la garantía del derecho de rectificación.

\section{Distinción entre información y opinión}

En el trabajo periodístico informar y opinar son dos actividades esenciales. Sin embargo, estas dos tareas no pueden ser entendidas de la misma manera. Por un lado, la información se refiere al resultado del abordaje de la realidad desde un enfoque objetivo. El periodista aborda la realidad social, política y económica de manera veraz e imparcial. De otro lado, la opinión encierra la dimensión subjetiva de la realidad del columnista, que se expresa a partir de sus valores y forma personal de ver las cosas.

A diferencia de la información sobre los hechos, que debe cumplir con los requisitos de veracidad e imparcialidad, la expresión de opiniones puede ser parcializada y en ocasiones equivocada, gozando de la misma protección constitucional del derecho a la libertad de expresión que las opiniones acertadas y ecuánimes (Corte Constitucional, T-312, 2015). La diferencia entre estas dos actividades es fundamental para garantizar el respeto al derecho a la información.

En la práctica, no es tan fácil determinar si lo que un medio trasmitió eran opiniones o informaciones. Por esta razón, la Corte Constitucional estableció una serie de parámetros para que los jueces puedan diferenciar estos dos conceptos de manera acertada. Los medios de comunicación deberán separar claramente los apartados destinados a transmitir información de las secciones destinadas a expresar opiniones. Esta separación no solo deberá ser gráfica, 
sino que también deberá estar expresada en la forma en que se presenta la opinión, que deberá mostrar su carácter subjetivo y parcializado (Corte Constitucional, T-1198, 2004).

Los medios de comunicación masiva tienen el deber de seguir estos parámetros y no tratar de confundir a la audiencia presentando opiniones en formato de información. La tarea de distinguir entre estas dos no está en cabeza únicamente del juez, sino también de los medios. Aquí radica la importancia de la forma de presentar el hecho.

\section{Veracidad de la información}

La veracidad se refiere a la correspondencia entre la información presentada y la realidad. Los periodistas antes de publicar la información deben realizar una tarea de corroboración del material que están presentando. Sin embargo, la Corte Constitucional es clara al establecer que toda la información que circula no puede ser totalmente exacta, ya que esto haría imposible la labor periodística (Corte Constitucional, T-260, 2010).

Dentro de este proceso de veracidad de la información, el comunicador debe realizar un proceso de verificación razonable, con lo cual no se le exige una prueba irrefutable, sino un comportamiento diligente en el ejercicio de su profesión. Esto es, esforzarse por presentar noticias constatando las fuentes; sin intención de perjudicar el buen nombre, el derecho al honor y la intimidad; $\mathrm{y}$, por último, que en su actuación no haya un interés por distorsionar la realidad, presentando hechos falsos como ciertos (Corte Constitucional, T-260, 2010).

Por tanto, las noticias transmitidas en los medios de comunicación masiva pueden no ser totalmente ciertas, sino que requieren de un ejercicio previo y razonable de verificación de la información por parte del comunicador. Si una vez publicada la información resulta que esta es falsa y vulnera los derechos fundamentales de un tercero, los medios tienen la obligación de publicar los hechos correctos. En el caso en que existan hechos de difícil constatación, ya sea por razones empíricas o de seguridad, no deberá presentarse la información como cierta o definitiva (Corte Constitucional, T-312, 2015).

La Corte Constitucional establece tres ejemplos representativos en los cuales los medios de comunicación masiva incumplen las cargas mínimas de veracidad establecidas constitucionalmente. En primer lugar, si el dato fáctico no corresponde con la realidad, es contrario a la realidad o fue publicado por la negligencia o la mala intención del emisor; si se presenta como un hecho cierto; $\mathrm{y}$, por último, si a partir de informaciones ciertas, se induce al lector a conclusiones falsas o erróneas (Corte Constitucional, T-312, 2015). 


\section{Imparcialidad}

Según la Corte Constitucional, el principio de imparcialidad de los medios de comunicación «envuelve una dimensión interpretativa de los hechos, la cual incluye elementos valorativos y está a mitad de camino entre el hecho y la opinión» (Corte Constitucional, T-080, 1993). La Corte indica que la presentación de noticias como relatos totalmente objetivos oculta la imposibilidad de eliminar elementos subjetivos en la presentación de los hechos, que deben ser analizados con reserva (Corte Constitucional, T-312, 2015).

La Constitución del 91 relacionó la exigencia de imparcialidad con el equilibrio informativo. Los periodistas se encuentran en la obligación legal de contrastar las fuentes consultadas, así como de consultar con diferentes expertos, en caso de ser necesario, presentando todas las perspectivas en el marco de un debate. Todo esto responde al derecho a la libertad de información que tiene el público, pues con el acceso a la información imparcial se podrán formar opiniones no sesgadas sobre un tema en específico (Corte Constitucional, T-312, 2015).

El Tribunal Constitucional ha advertido sobre los riesgos que supone la adopción acrítica de la posición mayoritaria por parte de los medios de comunicación masiva. En palabras de la Corte:

En este sentido, debe advertirse que la función estructural que cumple la libertad de expresión, y en particular la libertad de prensa, de crear condiciones para una real democracia deliberativa, dentro de la cual sea posible el ejercicio de control del poder, impone al medio de comunicación que establezca escenarios dentro de los cuales la opinión pueda ser confrontada por las contrapartes. El espacio deliberativo se ha de trasladar, de alguna manera, al ámbito periodístico. A fin de que el foro sea realmente público y democrático, en el cual se genera una opinión libre, no pueden faltar elementos propios del debate. La ausencia de contradictores torna a la audiencia en cautiva y con reducidas opciones para formarse su propia opinión sobre el tema debatido en el foro. Se trata, pues, de lograr un equilibrio informativo. (Corte Constitucional, T-391, 2017)

\section{Garantía del Derecho de Rectificación}

La garantía del derecho de rectificación se trata de una garantía de doble vía. Por un lado, la rectificación es un derecho que tiene el afectado por la información errónea o falsa para que esta sea corregida o aclarada. Por otro lado, es una obligación en cabeza del medio de comunicación de aclarar, actualizar o corregir la información emitida (Corte Constitucional, T-040, 2013). 
La Corte Constitucional afirma que el derecho a la rectificación no tiene la misma fuerza intimidatoria que el castigo penal, pues se centra más en la reparación del daño. Al ser una medida no invasiva, protege tanto el derecho al buen nombre y la honra, como el derecho a la libertad de expresión. Para que se conceda este derecho, no es necesario que haya una declaración de responsabilidad civil o penal previa, ni que se demuestre la negligencia al informar o la intención de causar un daño. Solo es necesario que se demuestre la falta de correspondencia entre la información y la realidad, su falta de fundamento o la tergiversación de la información. Sin embargo, si la noticia es injuriosa y se refiere a una persona en concreto, dando razones inexactas, la carga de la prueba no estará en cabeza del afectado, sino en el medio de comunicación (Corte Constitucional, T-040, 2013).

El principal propósito de esta figura es evitar que la afectación al buen hombre y la honra se prolonguen, por lo que la rectificación debe hacerse en un término razonable. Asimismo, no se interesa en indemnizar al afectado económicamente, sino que se enfoca en restablecer su buen nombre. Con este propósito, el medio de comunicación debe darle la misma importancia a la rectificación que a la noticia que ocasionó la afectación. Por último, esta vía de protección de los derechos de los afectados no excluye otras vías judiciales (Corte Constitucional, T-121, 2018).

El derecho a pedir rectificación no procede frente a una opinión, solamente frente a la información. En la rectificación, los medios de comunicación tienen el deber de reconocer explícitamente que se han equivocado; no basta con ofrecer un espacio en el medio de comunicación para que la persona presente su defensa. La herramienta aplicable es la rectificación, mas no la réplica. Asimismo, el medio no se puede limitar a leer un comunicado suscrito por la persona afectada.

En síntesis, la libertad de expresión es un derecho que cuenta con una amplia protección por el ordenamiento jurídico colombiano. Su respeto es fundamental para la preservación de la democracia y los fundamentos del Estado social de derecho. Sin embargo, los derechos no son absolutos, pues dependen del respeto de otros derechos igualmente valiosos, como es el caso del debido proceso. Por esta razón, el ejercicio de la libertad de expresión tiene que orientarse por los principios del proceso, los cuales imponen un límite a la información.

\section{PRINCIPIOS DEL PROCESO JUDICIAL}

Así como el derecho a la libertad de expresión es protegido supranacional, constitucional y legalmente, los procesos judiciales se encuentran goberna- 
dos por principios de igual importancia. Los principios que en la actualidad gobiernan el proceso judicial fueron ideados por la Ilustración. Uno de los fundamentos que tienen en común es la necesidad de garantizar el respeto al individuo frente al poder del Estado. Esta desconfianza se explica por la capacidad desbordada de la que gozaba el Antiguo Régimen, que podía disponer de la vida de sus súbditos, sin más control que la voluntad del soberano. El Estado de derecho cambió este fundamento divino del poder y lo reemplazó por el límite al poder y el respeto de las garantías de los individuos.

Dentro de estas garantías, se consagró el debido proceso como núcleo de las actuaciones judiciales y administrativas. Este derecho se compone de una serie de mandatos como son la presunción de inocencia; el derecho a ser juzgado conforme a leyes preexistentes al acto que se le imputa, ante juez o tribunal competente; el principio de favorabilidad en materia penal; y la nulidad de pleno derecho de la prueba obtenida con violación del debido proceso.

La jurisprudencia constitucional ha abordado el derecho al debido proceso en numerosas ocasiones, así como las garantías que se encuentran establecidas en el ordenamiento jurídico, mediante las cuales se protege a los individuos que participen en una actuación administrativa o judicial. Este derecho tiene como propósito defender los fines primordiales del Estado y la sujeción de las actuaciones del poder público a los procedimientos fijados por la ley (Corte Constitucional, C-641, 2002). La Corte Constitucional clasifica el derecho al debido proceso de la siguiente manera:

i. El derecho a la jurisdicción, que a su vez conlleva los derechos al libre e igualitario acceso a los jueces y autoridades administrativas, a obtener decisiones motivadas, a impugnar las decisiones ante autoridades de jerarquía superior, y al cumplimiento de lo decidido en el fallo;

ii. el derecho al juez natural, identificado como el funcionario con capacidad o aptitud legal para ejercer jurisdicción en determinado proceso o actuación, de acuerdo con la naturaleza de los hechos, la calidad de las personas y la división del trabajo establecida por la Constitución y la ley;

iii. el derecho a la defensa, entendido como el empleo de todos los medios legítimos y adecuados para ser oído y obtener una decisión favorable. De este derecho hacen parte el derecho al tiempo y a los medios adecuados para la preparación de la defensa; los derechos a la asistencia de un abogado cuando sea necesario, a la igualdad ante la ley procesal, a la buena fe y a la lealtad de todas las demás personas que intervienen en el proceso; 
iv. el derecho a un proceso público, desarrollado dentro de un tiempo razonable, lo cual exige que el proceso o la actuación no se vea sometido a dilaciones injustificadas o inexplicables;

v. el derecho a la independencia del juez, que solo es efectivo cuando los servidores públicos a los cuales confía la Constitución la tarea de administrar justicia ejercen funciones separadas de aquellas atribuidas al ejecutivo y al legislativo, $\mathrm{y}$

vi. el derecho a la independencia e imparcialidad del juez o funcionario, quienes siempre deberán decidir con fundamento en los hechos, conforme a los imperativos del orden jurídico, sin designios anticipados ni prevenciones, presiones o influencias ilícitas. (Corte Constitucional, C-341, 2014)

De estos derechos, los que se exponen a continuación son los que pueden entrar directamente en conflicto con el ejercicio de la libertad de expresión:

\section{Legalidad}

El principio de legalidad está en la base misma del Estado social de derecho, pues representó una conquista frente a la incertidumbre del antiguo régimen al trazar los límites del poder. De ahí que las actuaciones de los poderosos tuvieran que seguir un camino trazado con anterioridad, lo cual reduce la incertidumbre y posibilita el ejercicio de derechos. Frente a los procesos, las personas sometidas a la justicia solo podrán serlo si los actos que cometieron han sido previamente considerados como antijurídicos por la ley, garantizando de esta manera la protección de los derechos de los individuos frente al poder (Corte Constitucional, C-444, 2011).

Este principio regula el actuar del poder judicial; ningún juez puede iniciar o adelantar un proceso, alejándose de la normatividad previamente promulgada por el poder legislativo. Por tanto, el deber de los jueces de adelantar el proceso judicial en cumplimiento de lo dispuesto por la Constitución y la ley sustenta la obligatoriedad de motivar las decisiones judiciales de tal modo que se trate de una decisión en derecho (Corte Constitucional, C-091, 2017). De esta manera, el funcionario judicial al momento de tomar sus decisiones no debe más que obedecer los contenidos de la ley.

\section{Publicidad}

García-Perrote (2017) clasifica el principio de publicidad en tres niveles: las partes, los espectadores directos y la sociedad en general. El primer nivel se relaciona con el conocimiento de las actuaciones por parte de los intervinientes 
y las partes del proceso; el segundo nivel posibilita la asistencia de la ciudadanía a las audiencias; y el último nivel garantiza la publicidad del proceso ante la sociedad en general.

Este principio pretende aumentar la confianza y el control ciudadano a las actuaciones del poder público, evitando así la arbitrariedad y la injusticia (Barrero, 2001). A través de la observación ciudadana, se espera que los funcionarios judiciales, los testigos y los peritos se puedan sentir obligados a actuar con integridad. Asimismo, se procura promover la formación de la opinión pública frente a sucesos sociales, lo cual se ve reflejado en una mejora del espíritu cívico (Montalvo, 2012).

Este principio hace parte del núcleo del debido proceso, ya que posibilita el derecho a la defensa y la promoción de otras garantías por medio de la observación de la ciudadanía. La publicidad se refiere a todas las actuaciones y los documentos de la administración pública, a excepción de los que están sometidos a reservas. Procesalmente, se pueden encontrar excepciones como en el caso de los procesos llevados a cabo en el sistema de responsabilidad penal para adolescentes, en las audiencias reservadas de control de garantías y en las audiencias que son llevadas sin público (Corte Constitucional, C-641, 2002).

\section{Imparcialidad e independencia del poder judicial}

El funcionamiento del ordenamiento jurídico, con sus principios y valores, depende de la aplicación imparcial de sus preceptos jurídicos. Sin este principio, no tendría sentido la promoción de otros derechos, ya que la aplicación imparcial del derecho en la resolución de conflictos jurídicos permite la materialización del derecho a la igualdad y del principio de legalidad. En otras palabras, la imparcialidad es la base normativa de la justicia (Schedler, 2005).

Asimismo, las decisiones judiciales deben ser independientes, los funcionarios no deben ser presionados por órganos de otras ramas del poder público, incluida la rama judicial. De esta manera, se asegura que las decisiones sean tomadas en derecho y con respeto de la institucionalidad (Corte Constitucional, C-496, 2016). Entonces, la independencia se constituye en un primer paso para la garantía de las decisiones judiciales, faltando el segundo paso que ya no depende de razones objetivas, sino del funcionario judicial.

El segundo paso es el de la imparcialidad. Una vez se haya garantizado la independencia, el ordenamiento jurídico obliga a los funcionarios a tomar decisiones imparciales. La Corte Constitucional ha enfatizado que la imparcialidad es un asunto de honorabilidad, honestidad del juez y responsabilidad judicial, la cual está respaldada por el derecho a la igualdad, establecido en el 
artículo 13 de la Constitución Política de Colombia (Corte Constitucional, C496, 2016).

El derecho a la imparcialidad está clasificado en dos dimensiones. Por un lado, la imparcialidad objetiva indica que los casos sometidos a la consideración de los funcionarios judiciales no deben generarle un interés directo, ni indirecto por medio de un conocimiento anterior. Con esto, se está haciendo referencia a situaciones de carácter concreto, ya que no sería posible no tener opiniones sobre un tema de consideración general. Por otro lado, la imparcialidad subjetiva exige que el juzgador no tenga vínculos con ninguna de las partes, para lo cual se ofrece la posibilidad de declararse impedido o ser recusado (Corte Constitucional, C-762, 2009).

\section{Principio de la presunción de inocencia}

En desarrollo del artículo 29 de la Constitución Política, la Corte Constitucional caracteriza la presunción de inocencia como el derecho de todas las personas a ser tratadas como inocentes mientras no se demuestre lo contrario. Este derecho es exigible a todas las autoridades que en ejercicio de sus funciones impongan sanciones, evitando así la arbitrariedad. Asimismo, se evita la unilateralidad al decidir el caso, ya que la presunción de inocencia solo puede ser desvirtuada en medio de un proceso donde el sindicado tenga la posibilidad de defenderse en debida forma (Corte Constitucional, C-003, 2017).

Por esta razón, el juez debe partir de la inocencia del procesado, lo cual implica que la carga de la prueba está en manos de la institución que acusa y no en el sujeto que es sometido a la justicia, por lo que en caso de duda tendrá que ser absuelto. Este principio tiene una estrecha relación con el principio de imparcialidad, ya que el juez deberá abordar el caso sin prejuzgamientos de ningún tipo (Corte Constitucional, C-289, 2012).

\section{MEDIOS DE COMUNICACIÓN Y PROCESOS JUDICIALES}

\section{Mass media y Corte Constitucional}

La Corte Constitucional ha establecido jurisprudencialmente que, en el marco de un Estado social y democrático de derecho, los medios de comunicación y la sociedad en general tienen el derecho a denunciar públicamente hechos y actuaciones irregulares de las que tengan conocimiento, por lo que no deben esperar a que se resuelva judicialmente la situación. Incluso, los comunicadores pueden reprochar una conducta que se considere irregular, amañada o maliciosa, sin importar que esta haya sido resuelta en sentido contrario por parte 
de los funcionarios de justicia, ya que ni siquiera los poderes públicos tienen la última palabra frente al conocimiento y la rectitud (Cabral, 2016). De otro lado, la reserva de información no obliga ni a los periodistas ni a los medios de comunicación, lo que refuerza la protección a la libertad de expresión. En palabras de la Corte Constitucional:

(...) en principio, el mandato de reserva no vincula a los periodistas ni a los medios de comunicación. Lo anterior se explica por el papel de la prensa dentro del sistema democrático. A los medios de comunicación les corresponde cumplir con una función de control del poder público. Esta tarea no podría desarrollarse a cabalidad si los medios se conformaran con las informaciones que les fueran suministradas. Precisamente, la labor de control que desempeñan los medios exige que no se satisfagan con los comunicados oficiales y los datos entregados por las partes interesadas, sino que indaguen siempre más allá en busca de la verdad. (Corte Constitucional, T-066, 1998)

Sin embargo, esta búsqueda de la verdad debe realizarse dentro de los límites que impone la Constitución Política de Colombia. A pesar de que en Colombia el derecho a la libertad de expresión cuenta con una protección especial por parte de las autoridades judiciales, su ejercicio está sujeto a varias limitaciones y al seguimiento de reglas y procedimientos específicos. En el caso de la cobertura mediática a los procesos judiciales, la jurisprudencia de la Corte Constitucional advierte que toda la información que se dé en el marco de un proceso judicial debe tener condiciones mínimas de veracidad y credibilidad. Asimismo, explica que las críticas y opiniones a la administración de justicia no pueden limitarse dentro de una democracia constitucional sin una razón de peso que lo justifique (Corte Constitucional, T-066, 1998).

Una de las razones principales por los cuales el derecho a la libertad de expresión puede limitarse, se debe a las posibles afectaciones que podría causar la falta de veracidad e imparcialidad a los derechos fundamentales de los intervinientes en un proceso. En este sentido, la Corte Constitucional, refiriéndose a un caso específico, aclaró que:

Tratándose de hechos que han sido sometidos a investigación por parte de los entes de control y de los que se derivan imputaciones de conductas punibles, la Corte ha llamado la atención sobre el especial cuidado que se debe observar en el tratamiento de esta información. El noticiero estaba en su derecho y aún en su deber de informar sobre los hechos objeto de investigación, pero debió limitarse a hacer la exposición objetiva y escueta de los mismos absteniéndose de emitir una calificación jurídica que no se ha producido, derivada de una inferencia periodística. (Corte Constitucional, T$626,2007)$ 
La Corte Constitucional va más allá y expone cómo deben presentar la información sobre procesos judiciales los mass media. En su labor periodística, los medios deben «hacer la exposición objetiva y escueta de lo acaecido, absteniéndose de hacer análisis infundados y de inclinar, sin evidencias, las opiniones de quienes reciben la información» (Corte Constitucional, T-626, 2007). Además, en los procesos penales, deben adoptar una posición crítica e independiente frente a las partes en litigio, procurando que, al momento de presentar los hechos, no suenen a acusaciones. De manera que las comunicaciones trasmitidas no atenten en contra del buen nombre, ni de otros derechos fundamentales de los intervinientes en la contienda judicial (Corte Constitucional, T-626, 2007).

\section{Juicios paralelos}

Estas consideraciones jurisprudenciales parten de la fuerte influencia que ejercen los medios de comunicación en los procesos judiciales, que abordan las cuestiones penales extensamente en virtud del principio de publicidad de los procesos y de la libertad de expresión, lo cual trae una mayor audiencia para el medio, que a través del conocimiento que obtienen de las investigaciones sobre los procesos, inician un juicio paralelo en el que sacan y presentan sus propias conclusiones a una audiencia ávida de certeza. Eduardo Espín, citado por Burgos y Amaya, define a los juicios paralelos de la siguiente manera:

(...) el conjunto de informaciones aparecidas a lo largo de un periodo de tiempo en los medios de comunicación, sobre un asunto sub iudice a través de los cuales se efectúa por dichos medios una valoración sobre la regularidad legal y ética del comportamiento de personas implicadas en hechos sometidos a investigación judicial. Tal valoración se convierte ante la opinión pública en una suerte de proceso. Al cabo de un determinado periodo de tiempo, en el que han ido apareciendo informaciones sobre los hechos acompañados de juicio de valor más o menos explícitos, editoriales, contribuciones de personas ajenas a la plantilla de tales medios, las personas afectadas aparecen ante la opinión pública, o al menos ante un segmento de ellas, como inocentes o culpables. (2013)

Estos juicios pueden afectar el desarrollo y la conclusión de los procesos judiciales; la información ventilada y los juicios de valor de los medios de comunicación hacen que las personas involucradas en las investigaciones sean sentenciadas por la moral colectiva. En diversas ocasiones estos juicios colectivos no tienen ninguna fundamentación, son contrarios a las decisiones judiciales, las cuales se encuentran fundamentadas en investigaciones completas, imparciales y fundadas en el principio de legalidad (Burgos \& Amaya, 2013). 
En definitiva, los juicios paralelos no son otra cosa que los juicios de valor emitidos por los medios de comunicación masiva frente a la información obtenida en el desarrollo de un proceso judicial. Estos juicios paralelos son prematuros veredictos populares, que reflejan la dificultad de los medios de asistir a todas las audiencias y la falta de conocimiento jurídico de los comunicadores y periodistas (Gorini, 2016 ).

Esta clase de juicios en el marco de la protección al derecho a la libertad de expresión no solamente afectan el buen desarrollo de los procesos judiciales, sino que pueden causar afectaciones a otros derechos subjetivos de los involucrados en los procesos, como el honor o el buen nombre. En muchas ocasiones, la falta de preparación judicial de los comunicadores, y en general de los medios, hace que el principio de la libertad de prensa pase por encima de otros principios constitucionalmente reconocidos, como lo es el debido proceso.

Uno de los principales problemas de los juicios paralelos es que son precisamente estos los que llegan a conocimiento y debate de la opinión pública, lo cual hace que la sociedad se forme una imagen errónea del proceso. Esto puede causar que el juez se sienta presionado para fallar en un sentido que satisfaga la opinión pública, por el temor de ser blanco de críticas, ya que, si el juez falla en derecho y en contra de la opinión pública, su idoneidad será puesta en duda, lo cual es amparado bajo el principio de la libertad de expresión (Cabral, 2016). De esta manera, se afecta el principio de imparcialidad en las decisiones judiciales, lo cual tiene repercusiones negativas en otros derechos como el de legalidad y presunción de inocencia, afectando no solo el caso en concreto, sino al sistema jurídico en general, principios estos que fueron expuestos en el anterior acápite.

\section{CONCLUSIÓN}

El Sistema interamericano de Derechos Humanos le da un lugar central al derecho a la libertad de expresión, pues considera que este derecho es garante de la promoción de la opinión pública en las sociedades democráticas. Asimismo, asegura que la protección de este derecho debe tener en cuenta su dimensión objetiva y subjetiva, es decir, el derecho a expresarse y el derecho a recibir información verídica e imparcial. La última dimensión es la que este texto encontró más problemática, ya que depende del ejercicio correcto que los medios de comunicación hagan de su derecho a informar.

La Corte Constitucional asegura que a pesar de ser un derecho esencial para el Estado social de derecho no está exento de limitaciones, que deben respetar 
otros derechos de igual importancia como los del debido proceso. Sin embargo, las limitaciones que se imponen a los medios de comunicación se dirigen primordialmente a la información, exigiendo que esta sea verídica e imparcial, lo cual ignora que a través de la opinión también se puede formar juicios paralelos. Por esta razón, la solución a este tipo de juicios no puede ser dada por el derecho, pues la importancia del principio de la libertad de expresión y la multiplicidad de medios en los cuales se puede formar la opinión hacen inocuos los esfuerzos de cualquier tribunal.

Por otro lado, ante la inviabilidad de una respuesta jurídica efectiva, se deben tomar otras decisiones que tengan un impacto real, como puede ser el caso del fortalecimiento de las competencias del poder judicial, que es en últimas quien recibe la presión generada por los juicios paralelos. Además, la agencia ciudadana es esencial para cambiar el uso de los medios de comunicación; sin una promoción del ejercicio de la ciudadanía, la relación entre sociedad y medios de comunicación será de dependencia. Por último, es claro que en lugar de ser el derecho un límite a los juicios paralelos, es el derecho el que está limitado para responder a estos.

\section{REFERENCIAS}

Barrero Ortega, A. (2001). Juicios paralelos y Constitucion: su relación con el Periodismo. Ámbitos, (6), 171-189. doi:http:/ / dx.doi.org/10.12795/Ambitos.2001.i06.11

Burgos, A. \& Amaya, J. (2013). La influencia mediática en las decisiones judiciales penales. (Monografía). Pontificia Universidad Javeriana, Bogotá, Colombia.

Cabral, L. M. (2016). Poder judicial y medios de comunicación. Una difícil relación. En Bourdin, M. \& Méndez, P. (Comp.), Justicia Argentina online. El nuevo modelo comunicacional (pp. 53-68). Buenos Aires.

Carvajal, J. (2019). Seguridad y construcción del control social: la cárcel y el estado social de derecho. Seguridad, Revista Opción, año 35, Especial nro. 25, 774-814. ISSN 1012- 1587/ISSNe: 2477-9385

Comisión Interamericana de Derechos Humanos. (s. f.). Declaración de Principios sobre la Libertad de Expresión. Obtenido de https:/ / www.cidh.oas.org/basicos/ declaracion.htm

Comisión Interamericana de Derechos Humanos. (2000). Antecedentes e Interpretación de la Declaración de Principios. Obtenido de http:/ / www.oas.org/es/cidh/ expresion/showarticle.asp?artID $=132 \& I I D=2$ 
Comisión Interamericana de Derechos Humanos. (2010). Marco Jurídico Interamericano sobre el Derecho a la Libertad de Expresión. Obtenido de http:/ / www.oas.org/ es/cidh/expresion/docs/cd/sistema_interamericano_de_derechos_humanos/ index_MJIAS.html

Corte Constitucional. (05 de marzo de 1998). Sentencia T-066. [MP Eduardo Cifuentes Muñoz].

Corte Constitucional. (01 de diciembre de 2004). Sentencia T-1198. [MP Rodrigo Escobar Gil].

Corte Constitucional. (25 de agosto de 2007). Sentencia T-626. [MP Jaime Córdoba Triviño].

Corte Constitucional. (16 de abril de 2010). Sentencia T-260. [MP Mauricio González Cuervo].

Corte Constitucional. (28 de enero de 2013). Sentencia T-040. [MP Jorge Ignacio Pretelt Chaljub].

Corte Constitucional. (22 de mayo de 2015). Sentencia T-312. [MP Jorge Iván Palacio Palacio].

Corte Constitucional. (22 de mayo de 2017). Sentencia T-391. [MP Manuel José Cepeda Espinosa].

Corte Constitucional. (09 de abril de 2018). Sentencia T-121. [MP Carlos Bernal Pulido].

Corte Constitucional. (23 de enero de 1996). Sentencia C-022. [MP Carlos Gaviria Díaz].

Corte Constitucional. (04 de junio de 2014). Sentencia C-341. [MP Mauricio González Cuervo].

Corte Constitucional. (18 de enero de 2017). Sentencia C-003. [MP Aquiles Arrieta Gómez].

Corte Constitucional. (15 de febrero de 2017). Sentencia C-091. [MP María Victoria Calle].

Corte Constitucional. (19 de abril de 2017). Sentencia C-220. [MP José Antonio Cepeda Amarís].

Corte Constitucional. (13 de agosto de 2002). Sentencia C-641, 2002. [MP Rodrigo Escobar Gil]. 
Corte Constitucional. (25 de mayo de 2011). Sentencia C-444, 2011. [MP Juan Carlos Henao Pérez].

Corte Constitucional. (14 de septiembre de 2016). Sentencia C-496, 2016. [MP María Victoria Calle Correa].

Corte Constitucional. (29 de octubre de 2009). Sentencia C-762, 2009. [MP Juan Carlos Henao Pérez].

Corte Constitucional. (18 de abril 2012). Sentencia C-289, 2012. [MP Humberto Antonio Sierra Porto].

Chomsky, N., \& Herman, E. (2000). Los guardianes de la libertad. Barcelona: Editorial Crítica.

Garcia-Perrote Forn, M. E. (2017). Juicios Paralelos. Barcelona: Atelier, Libros Jurídicos.

Gorini, J. L. (2016). La publicidad de la etapa de prueba de los juicios penales y el fortalecimiento institucional del Poder Judicial. En Bourdin, M. \& Méndez, P. (Comp.), Justicia Argentina online. El nuevo modelo comunicacional (pp. 105-114). Buenos Aires.

Montalvo Abiol, J. C. (2012). Los Juicios Paralelos en el Proceso Penal: ¿Anomalía democrática o mal necesario? Universitas. Revista de Filosofía, Derecho y Política, (16), 105-125.

Oficina de la UNESCO en Montevideo. (s. f.). Libertad de expresión. Recuperado el 01 de 04 de 2021, de http://www.unesco.org/new/es/office-in\%20montevideo/ comunicacion-e-informacion/libertad-de-expresion/

Schedler, Andreas. (2005). Argumentos y observaciones: de críticas internas y externas a la imparcialidad judicial. Isonomía, (22), 65-95.

Sozzo, M. (2018). Populismo Penal. Historia, Balance, Dilemas y Perspectivas de un Concepto. En E. Escalante, Política Criminal Mediática: Populismo penal, Criminología Crítica de los Medios y de la Justicia Penal (págs. 23-68). Bogotá: Ibáñez.

Vattimo, G. (1990). La sociedad Transparente. Bercelona: Paidós Ibérica.

Zaffaroni, E. (2018). La Cuestión Criminal. Bogotá: Ibáñez. 
